\title{
Relevance of the automated systems of environmental monitoring in the implementation of the best available technologies
}

\author{
Aleksander Maslennikov ${ }^{1, *}$, Aleksander Egorov ${ }^{1}$, Ilya Zubkov ${ }^{2}$ \\ ${ }^{1}$ Nizhny Novgorod State Technical University named after R.E. Alekseev, 603950, 24 Minin str., \\ Nizhny Novgorod, Russia \\ ${ }^{2}$ Dzerzhinsk Polytechnic Institute, Nizhny Novgorod State Technical University named after R.E. \\ Alekseev, 606026, 49 Gaidar str., Dzerzhinsk, Russia
}

\begin{abstract}
The current state of the environment causes increasing concerns. At the same time, the tasks of economic development require expansion of industrial production, which in turn increases the burden on the environment. The solution to this contradiction is seen in using the best available technologies (BAT) as an economically more effective alternative to "green" technologies. Since the best available technologies do not involve the abandonment of the use of hazardous process substances, environmental monitoring systems that show the level of environmental contamination from them should be the most important concomitant element of these technologies. Solid-state chemical sensors can be used as the basis of such systems. To achieve high technical efficiency, the systems must be automatic or at least automated that will increase the level of public confidence in their work.
\end{abstract}

The newest paradigm does not require, as a few years earlier, the mandatory recognition and implementation of the concept of sustainable development of facilities. The reasons for this lie in the overall situation of socio-economic instability, and the inability of national governments to effectively manage the resource base that they have at their disposal. Considerations of the selfish nature are increasingly coming to the forefront, when, for the sake of achieving decisive military and political advantages, certain countries or coalitions consciously go on undermining the established societies and their habitat.

At the same time, some elements of the concept of sustainable development, arising from the general evolutionary logic, can find practical implementation. Social, environmental and economic factors are rightly attributed to such elements, and in certain cases it is appropriate to consider the first and second factor in indissoluble connection, thereby emphasizing the growing role of environment in the realization of a person's abilities and opportunities in the society.

As for the economic factor, its impact should be viewed in two ways, since on the one hand, without economy it is impossible to solve any environmental problem, but on the

*Corresponding author: mavdoc@rambler.ru 
other hand, the economic factor is one of the obstacles to the environmental well-being of the society.

The Strategy for Environmental Safety of the Russian Federation for the period until 2025, approved by the Decree of the President of the Russian Federation of April 19, 2017 No. 176, presents a generally negative assessment of the current state of environmental security. It is noted that as a result of past economic and other activities, over 30 billion tons of production and consumption wastes were accumulated. Based on the results of the inventory of territories, 340 objects of the accumulated harm to the environment, which are a source of potential threat to life and health of people, have been identified. At the same time, about 4 billion tons of production and consumption waste are generated annually, of which 55-60 million tons are solid domestic waste. The amount of waste that is not involved in the secondary economic turnover but is located in landfills and dumps increases that leads to the withdrawal of productive agricultural lands from circulation. About 15,000 authorized waste disposal facilities occupy an area of about 4 million hectares, and this territory is increasing by 300-400 thousand hectares annually [1].

Serious concerns are caused by the environmental situation in the cities and adjacent territories, where $74 \%$ of the population of the Russian Federation lives. Here the environment is exposed to the most significant negative impact, the sources of which are recognized objects of industry, energy and transport, as well as objects of capital construction. Some 17.1 million people that is $17 \%$ of the urban population of the Russian Federation, live in the cities with a high and very high level of air pollution [1].

Strategic assessments are reflected in the federal legislation, trying not only to declare the need for a safe environment, but also to form a mechanism for identifying and eliminating the harmful effects of adverse social and environmental factors on human beings. For this purpose, a system of social and hygienic monitoring was established, which involves the collection and analysis of statistical data that are received by the Russian Federal Service for Consumer Protection from various ministries and departments. An attempt has been made to set specific parameters, the achievement of which will make it possible to judge on the formation of ecologically safe and comfortable environment in the places where people live, work and rest, and reduce the incidence caused by adverse environmental conditions. Thus, the program "Environmental Protection" for 2012-2020, approved by the Russian Federation Government Decree of April 15, 2014 No. 326, provides for a reduction in the volume of emissions of pollutants from stationary sources per GDP value by 1.3 times [2].

Herewith, there are suspicions that the declared values are nothing more than a declaration [3], not confirmed by real mechanisms of implementation in the situation of constantly growing unfavorable factors, primarily motorization of the population, operation of power plants and production of industrial enterprises.

The way out of this contradictory situation is seen on the path of introducing the "green economy", where the "win-win" principle dominates, meaning that socio-economic projects should provide for the solution of environmental problems, and environmental projects should ensure a positive social and economic effect. Accordingly, the "green economy" allows stimulating the investment process in a sparing way, ensuring the use of the BAT.

Table 1 [4] provides a comparison of the criteria and the main features of "green" technologies and the BAT. As it follows from the Figure 1, the criteria for "green" production and the criteria for selecting the BAT are based on the close concepts and include rational consumption of raw materials, materials and water; ensuring high resource and energy efficiency; application of low-waste processes; minimization of emissions; refusal to use especially hazardous substances in technological processes; and the possibility of re-generation and re-use of substances utilized in production. These requirements have proven their effectiveness in different countries and regions of the world. 
Their implementation has allowed not only reducing the negative impact on the environment, but also introducing innovative solutions in the industry of the EU member states, the USA, Canada, South Korea, Taiwan, etc. Bringing requirements for large industries to a single "environmental denominator", issuing complex environmental permissions (CEP) on fair and unified conditions is a necessary step in the stage-by-stage environmental and technological modernization of the economy.

Table 1. Comparison of "green" technologies and the BAT.

\begin{tabular}{|l|l|}
\hline \multicolumn{2}{|c|}{ Criteria and main features of production technologies } \\
\hline \multicolumn{1}{|c|}{ "Green" production technologies } & \multicolumn{1}{c|}{ Best available technologies } \\
\hline - There is nothing absolute. & - Rational consumption of raw materials, \\
- Everything is relative. & - High materials and water. \\
- Resource and energy efficiency: & Application of low-waste processes; \\
- Higher than before the introduction of & - Possibility of re-generation and re-use of \\
new solutions, and environmental and & substances in processes; \\
energy management systems in other & - Requirements are determined as a result \\
processes. & of a comparative analysis of the state of \\
Minimum emission of toxic substances: & industries. \\
- Minimum or lower than in other & - Use of substances that are least hazardous \\
processes; & for humans and the environment in the \\
- The use and / or formation of toxic & processes: A Ability to reduce emissions associated \\
substances is excluded or reduced; & with the process; \\
- Environmental protection solutions & - Refusal from especially dangerous \\
(technology) are used. & substances. \\
- Safe and lean manufacturing: & Reducing the likelihood of accidents: \\
- Preventing emergency situations and & - Evidence of successful application of \\
preparing to them; & comparable processes, facilities, \\
- Efficient use of all resources. & management methods in a commercial scale; \\
& - Economic acceptability of technology \\
& for the industry. \\
\hline
\end{tabular}

Clear, justified, achievable criteria and the BAT requirements form the basis for an objective assessment of the environmental performance and resource efficiency of enterprises, setting goals for the consistent improvement of the achieved indicators and, finally, a comparative analysis of the environmental friendliness of industries within the sectors, regardless of the specifics of national legislation or regional peculiarities.

In Russia, the BAT is both a mechanism for environmental regulation and for industrial policy. The application of the BAT is wider considered in our country (Figure 1) [4], than in the European Union, where they are the basis of the system for issuing the CEP to industrial enterprises.

The transition to the BAT in Russia can potentially be an incentive for the development of domestic engineering, the solution of the task of import substitution, and the localization of equipment production through the creation of a new domestic market for Russian suppliers of equipment meeting the requirements of the BAT. Such synergy will allow stimulating the modernization of production while minimizing its negative impact on the environment and with a significant increase in resource efficiency that is, making a "shift" towards the development of more "green" production. Thus, dissemination of economically accessible and environmentally sound technological and technical solutions, as well as management techniques aimed at the introduction of resource-saving and low-waste production, technological re-equipment of enterprises, and the gradual decommissioning of 
facilities with obsolete, environmentally hazardous equipment is the meaning of the transition to the BAT in Russia.

\section{BAT}

\begin{tabular}{|l|}
\hline $\begin{array}{l}\text { Modernization of existing } \\
\text { production facilities }\end{array}$ \\
\hline
\end{tabular}

The emergence of new high-performance sites

Creation of modern domestic equipment
Construction of production capacities meeting the world's resource-saving indicators

Improvement of the ecological situation in the industrialized centers of Russia

Enhancing the competitiveness of the Russian economy

\section{Creating modern domestic equipment}

Fig. 1. The best available technologies in the context of environmental and industrial policies.

A number of municipal entities in the Russian Federation are practically "doomed" to large-scale implementation of the BAT, since without this they will not be able to solve their key social and economic problems in a comprehensive manner. For example, the former "capital" of Soviet chemistry, the urban district of Dzerzhinsk, Nizhny Novgorod region, in the industrial zone of which the content of a phenol hazardous to health significantly exceeds the maximum permissible standards constitutes one of such problems. In addition, the city's air is stably contaminated with ammonia, nitrogen dioxide, and suspended substances. Although in the last five years the level of air pollution has dropped from "very high" in 2012 to "increased" in 2016, the situation remains difficult. The task of ensuring environmental safety is very relevant that is reflected in the "Strategy for socioeconomic development of the urban district of Dzerzhinsk until 2030", where, in particular, is emphasized the need for the following:

- Identification of all territories exposed to chemical pollution at a scale that is dangerous to the environment and the population, and their localization on the terrain;

- Inventory of environmentally hazardous production facilities, structures and waste disposal sites;

- Formation and maintenance of cadastres of environmentally hazardous facilities at the municipal level;

- Inventory of the territory for the identification and special protection of natural complexes that perform especially important environment-forming functions and have a special recreational and health value;

- Rehabilitation of territories affected by negative economic activity [5].

When assessing the environmental situation of settlements and areas adjacent to them directly, the value of the maximum permissible concentration (MPC) of a hazardous substance that pollutes the atmosphere of a locality is used as the initial criterion. The MPC is the maximum allowable impurity concentration for the populated areas, established by the Chief Sanitary Doctor of the Russian Federation [6].

The degree of contamination is determined by the values of the average and maximum single concentrations of impurities and is estimated when comparing the actual concentrations of impurities in air with the MPC. The average concentrations are compared 
with the MPC for the average daily and annual MPCs, and the maximum of the specifically measured (one-time) concentrations - with the maximum one-time MPC. Although knowledge about the level of atmospheric pollution is not able to reduce pollution, it is the first step towards solving this issue.

To assess the state of the environment, it is necessary to know the current values of the concentrations of all substances of interest. It is obvious that at present any air monitoring system functioning within the BAT framework should be at least automated. Taking into account the requirements of the Federal Law 219-FZ "On Amendments to the Federal Law "On Environmental Protection", in the case of BAT implementation in an enterprise of the first category of hazard, the sources of pollution should be equipped with automatic gas analyzers with automatic transmission of indication to federal supervisory authorities [7]. The determination of the concentrations of air pollutants can be carried out by various methods.

First of all, these are traditional chemical-analytical methods, including analysis with the use of liquid absorbers, reagents, indicator and colored tubes, indicator strips and tape gas analyzers. These methods are based on the use of specific (selective) chemical reactions and interactions between the desired atmospheric pollutant and the one-time element of the analytical system. The main drawbacks of these methods are their manual implementation, which does not allow the effective utilization of methods as components of automated monitoring systems (AMS), as well as considerable time spent for sample preparation and implementation of the chemical analysis itself [8].

The second group of methods is instrumental methods, including gas chromatography, mass spectrometric, optical and optical-acoustic methods of gas analysis. Universal gas analyzers are utilized for implementing these methods that in many cases allow determining various gas components with high sensitivity and selectivity. In some cases, the analyses are characterized by a sufficiently high speed. However, as a rule, these devices are of stationary type, characterized by the complexity of their design and analysis technologies, and relatively high energy consumption and high cost. The main problem is that they require qualified operator support, and therefore they also cannot be fully included in the AMS.

The third group of methods is sensory methods based on the use of various chemical gas sensitive sensors. Chemical sensor is a device, usually made with the application of microelectronics technology that transforms the chemical composition of the medium into an electrical, optical or frequency output signal. Compactness and low cost are the advantages of the use of chemical sensors in gas analysis, as well as no need for the operator's support, ease of their inclusion in the AMS and good operational properties of sensors in terms of sensitivity, speed and stability.

In recent years, significant changes have taken place in the gas analysis technologies, related, as in many other fields of technology, to the development of information technologies, especially those using artificial intelligence elements.

The analysis of the principles of the sense of smell of various living beings functioning made it possible to formulate approaches to the creation, on the basis of sensors, of technical means for determining the gas composition comparable in their ability to recognize with biological analogs, that are called the hardware-software complex (HSC) of the «electronic nose» (EN) type. The work of [9] was one of the first studies that initiated this direction of gas analysis.

The HSC EN can be built on the basis of low-selectivity chemical sensors with cross sensitivity. Based on the results of processing their signals, it is possible to draw conclusions about the gas composition of the mixture being analyzed. The design of the HSC EN can allow «tuning» it to a specific task by quickly changing the set of sensors 
[10]. At the same time, high-selectivity sensors can be included in the HSC EN that, as a rule, permit determining certain gases reliably and with high sensitivity.

The major component of the HSC EN is the algorithms for recognition of images used for the labeling of the elements of the analyzed mixtures and determining their amounts based on the array of sensor signals. In particular, among the multidimensional data processing methods are the following: multivariate calibration discriminant factorial analysis, component analysis, absorption analysis, Duncan's multi-rank criterion, canonical correlation analysis, etc.

These methods allow, based on the results of processing several signals of different sensors characterizing the chemical composition of the gas mixture, to conclude of what it is composed. This takes into account different sensitivity of sensors to the components of the mixture, that is, the selectivity, the differences in the dynamics on various components that allows determining various single substances and various combinations of these substances, i.e. smells, with one set of sensors. Such systems are developed and used in many fields, from the search for drags and explosives, to the evaluation of the quality of wine [11] and the assessment of the environmental friendliness of consumer products [12].

With all the diversity of atmospheric pollutants, it is possible to distinguish a group of substances most often encountered in the atmosphere of cities. These are the six main priority air pollutants: ammonia, sulfur dioxide, hydrogen sulfide, nitrogen dioxide, carbon monoxide and suspended substances (dust). Their ubiquitous distribution is due to different reasons, but is present, however, in the ecosystem of most cities. So ammonia and, especially, hydrogen sulfide are indispensable satellites of sewerage systems, nitrogen oxides and carbon monoxide - of motor transport, sulfur dioxide - of fuel and energy systems and plants. A large amount of dust is a consequence of the municipal lack of urban amenities, lack of green spaces in their territory and a large amount of open ground. In addition to these substances, in the atmosphere of cities there are pollutants, characteristic for this or that particular city, because of the enterprises operating on its territory, with their specific technical processes and used substances.

Therefore, the HSC of atmospheric air should include both a standard gas analytical unit for the determination of priority air pollutants substances, and special elements that determine the presence of pollutants specific for a given area. Consequently, the HSC should contain several (up to ten or more) sensitive elements capable to detect all the main pollutants of the atmosphere. And these are compact, sensitive, energy-efficient, relatively inexpensive solid-state chemical sensors that are the most promising for the use in the atmospheric air HSC.

Thus, the following main conclusions can be drawn:

1. In order to improve the environmental situation, it is necessary to modernize existing production technologies and equipment.

2. The BATs are economically more attractive in comparison with "green" technologies.

3. Environmental monitoring systems that directly belong to the BAT or operate in parallel with the BAT are to be their important element.

4. The importance of environmental monitoring systems is explained, among other things, by their social aspect that confirms the acceptability of environmental conditions for the existence of socium.

5. Environmental monitoring systems should be at least automated, to increase both technical efficiency and the level of public confidence in them.

6. Due to a set of their parameters, solid-state chemical sensors can be used as a basis for building the HSC. 
The work was supported by the Ministry of Education and Science of the Russian Federation. The Agreement No. 14.577.21.0144 of November 28, 2014. The unique project ID is RFMEFI57714X0144.

\section{References}

1. The Strategy of Ecological Safety of the Russian Federation for the period until 2025, approved by the Decree of the President of the Russian Federation of 19.04.2017 №176 (http://docs.cntd.ru/document/420396664, Moscow, 2017)

2. The State Program of the Russian Federation on Environmental Protection for 20122020, approved by Resolution of the Government of the Russian Federation of April 15, 2014 No. 326 (as amended by the Russian Federation Government Resolution No. 397 of March 31, 2017) (http://docs.cntd.ru/document/499091755, Moscow, 2014)

3. B. A. Revich, Environment and public health (Analytical Center under the Government of the Russian Federation, Moscow, 2017)

4. T. V. Guseva, Best available technologies (Analytical Center under the Government of the Russian Federation, Moscow, 2017)

5. The strategy of social and economic development of the urban district of the city of Dzerzhinsk, Nizhny Novgorod region until 2030, approved by the decision of the city Duma of Dzerzhinsk, Nizhny Novgorod region of June 18, 2015, No. 948 (http://www.dumadzr.ru/files/strategia.pdf, Nizhny Novgorod 2015)

6. The maximum permissible concentrations of pollutants in the air in populated areas (Hygienic standards, Moscow, 2003)

7. Federal Law No. 219-FZ of July 21, 2014 on Amendments to the Federal Law on Environmental Protection and Certain Legislative Acts of the Russian Federation (Moscow, 2014)

8. $R D$ 52.04.186-89 - guidance on controlling atmospheric pollution (USSR Gosgidromet, Moscow, 1991)

9. K. Persaud, G. Dodd, Nature, 299 (1982)

10. L. F. Shcherbakova, A. V. Shantrokh, I. V. Egorov, A. A. Shcherbakov, Russian Chemical Journal, LI2 (2007)

11. T. A. Kuchmenko, R. P. Lisitskaya, A. A. Shuba, Analytics and Control, 18, 4 (2014)

12. T. A. Kuchmenko, E. V. Drozdova, Analytics and Control, 18, 1 (2014) 